2. Lee HA, Cheng YT, Wu VC, Chou AH, Chu PH, Tsai FC, et al. Nationwide cohort study of mitral valve repair versus replacement for infective endocarditis. J Thorac Cardiovasc Surg. 2018;156:1473-83.e2.

3. Antunes MJ. Mitral valve repair versus replacement for infective endocarditis. What is better in the "real world"? J Thorac Cardiovasc Surg. 2018;156:1471-2.

4. Antunes MJ. The real world: what does it mean? Do I belong to it? J Thorac Cardiovasc Surg. 2017;154:1913-4.

5. Toyoda N, Itagaki S, Egorova NN, Tannous H, Anyanwu AC, El-Eshmawi A, et al. Real-world outcomes of surgery for native mitral valve endocarditis. J Thorac Cardiovasc Surg. 2017;154:1906-12.e9.

https://doi.org/10.1016/j.jtcvs.2019.02.044

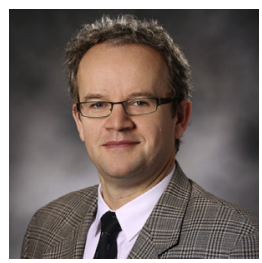

\section{DO NOT DESPAIR, AND CONTINUE TO IMPROVE REPAIR}

\section{Reply to the Editor:}

I read with interest the astute commentary of Nappi and colleagues ${ }^{1}$ regarding the underutilization of mitral valve repair in infective endocarditis (IE) reported in the study by Lee and associates. ${ }^{2}$ Nappi and colleagues ${ }^{1}$ point to the heterogeneous approaches to mitral valve endocarditis, driven mostly by hospital and operator experience, and call for consideration of referral to highly specialized centers. As increasing clinical evidence suggests improved outcomes with mitral repair in $\mathrm{IE}^{3}$ these considerations should not go unheeded. What is optimal, however, should be balanced against that which is practical and attainable. It is important to remember that surgical IE mitral valve disease carries a mortality risk of approximately $10 \%$ for valve replacement, ${ }^{2,3}$ representing high-risk pathology. Although perioperative survival may be better with valve repair, the sickest patients usually undergo replacement because of the degree of valvular destruction or hemodynamic compromise. In the absence of randomized data, one can conjecture that mitral repair is optimal, yet the patient substrate may be substantially different. Regionalization of subspecialty services or referent centers may offer a viable solution in centralized health care delivery systems; in the United States, however, this may be difficult to achieve. In a report from the Society of Thoracic Surgeons on mitral valve surgery in the United States from 2000 through 2007, Gammie and colleagues ${ }^{4}$ reported that 7967 operations for mitral IE were performed across the study period by 910 US centers. This approximately equates to 1 mitral IE operation per center per year. High-volume centers with extensive experience in complex mitral valve repair may not be in immediate proximity, and delay of treatment must be counterbalanced against emerging data suggesting that early surgical treatment of mitral IE provides improved outcomes. ${ }^{5}$ The more telling data from the Society of Thoracic Surgeons
Author has nothing to disclose with regard to commercial support.

report elucidated mitral valve repair rates for isolated primary mitral operations that ranged from $51 \%$ to $69 \%$ across the study period when patients with mitral stenosis were excluded. Perhaps here is where the surgical community's efforts should be focused to increase repair rates for more common and less challenging pathology, to standardize the surgical experience, and to equip the individual surgeon better to face the complexity of infective pathology. Partial homograft replacement of the mitral valve may be performed at few centers throughout the world, ${ }^{6}$ but facility with the most common repair techniques will suffice for most repairable valves with IE. This process appears to be progressively taking shape, because mitral repair rates for IE have doubled during a span of 12 years in New York State according to statewide data. ${ }^{7}$ The solution to realizing the potential of mitral valve repair in IE may therefore be education and exposure, rather than compartmentalization and subspecialization.

Tomasz A. Timek, MD, PhD

Division of Cardiothoracic Surgery Spectrum Health

Michigan State University College of Human Medicine Grand Rapids, Mich

\section{References}

1. Nappi F, Spadaccio C. Mitral valve endocarditis-unrealized expectations for repair of mitral valve. J Thorac Cardiovasc Surg. 2019;158:e31-2.

2. Lee HA, Cheng YT, Wu VC, Chou AH, Chu PH, Tsai FC, et al. Nationwide cohort study of mitral valve repair versus replacement for infective endocarditis. J Thorac Cardiovasc Surg. 2018;156:1473-83.e2.

3. Harky A, Hof A, Garner M, Froghi S, Bashir M. Mitral valve repair or replacement in native valve endocarditis? Systematic review and meta-analysis. J Card Surg. 2018;33:364-71.

4. Gammie JS, Sheng S, Griffith BP, Peterson ED, Rankin JS, O'Brien SM, et al. Trends in mitral valve surgery in the United States: results from the Society of Thoracic Surgeons Adult Cardiac Surgery Database. Ann Thorac Surg. 2009;87: 1431-7; discussion 1437-9.

5. Kang DH, Kim YJ, Kim SH, Sun BJ, Kim DH, Yun SC, et al. Early surgery versus conventional treatment for infective endocarditis. N Engl J Med. 2012;366: 2466-73.

6. Olivito S, Lalande S, Nappi F, Hammoudi N, D'Alessandro C, Fouret P, et al. Structural deterioration of the cryopreserved mitral homograft valve. J Thorac Cardiovasc Surg. 2012;144:313-20.

7. Toyoda N, Itagaki S, Egorova NN, Tannous H, Anyanwu AC, El-Eshmawi A, et al. Real-world outcomes of surgery for native mitral valve endocarditis. J Thorac Cardiovasc Surg. 2017;154:1906-12.e9.

https://doi.org/10.1016/j.jtcvs.2019.02.082 